\title{
Panoramapp! Um passeio virtual por panoramas do Rio de Janeiro
}

Panoramapp! A virtual tour by the panoramas of Rio de Janeiro

\author{
> Thiago Leitão de Souza \\ FAU/UFRJ, Rio de Janeiro, Brazil \\ leitao.thiago@gmail.com
}

\begin{abstract}
Since the great popularity of smartphones and tablets, many applications have been developed to create digital panoramas. However, its focus is turned for the seamless of the pictures and not what we can explore and understand of its different subjects. This article intends to investigate the use of a new concept of an app for digital panoramas. We assume that Panoramapp! can broaden the understanding the history of the cities by its panoramas and panoramic views, an alternative way to develop an iconographic hyper document of the central area of the city of Rio de Janeiro.
\end{abstract}

Keywords: Panoramapp; panorama; Rio de Janeiro; história da cidade.

\section{A cidade e a experiência imersiva}

A década de oitenta é marcada pelo aperfeiçoamento do desenho digital: a Realidade Virtual e os videogames passaram a ter um desenho mais elaborado e um maior grau de representação (GRAU, 2007). Tal afirmação está diretamente relacionada ao desenvolvimento das interfaces gráficas dos computadores, baseadas essencialmente na interatividade e na imersão entre o usuário e computador. A imagem virtual torna-se cada vez mais real e os sistemas ficam mais inteligíveis e de mais fácil acesso, contribuindo para novas reflexóes na representação digital da Arquitetura e da Cidade.

No entanto, quase três décadas nos separam do aprimoramento desta primeira verossimilhança. A internet se consolidou como o novo paradigma da contemporaneidade, alterando sensivelmente a forma de acessar e de se relacionar com a informação no mundo digital. A experiência em primeira pessoa tornou-se uma importante condição, constituindo-se como a principal base de uma nova imersão entre usuário e máquina (CALLEJA, 2011). Os sistemas computacionais evoluíram, passaram a estar além das telas fixas dos computadores e mais disseminados no cotidiano.

Recentemente, diversas ferramentas digitais vêm sendo desenvolvidas para interpretar temas e disciplinas relacionadas à cidade e ao Urbanismo podendo ser acessadas destes mesmos equipamentos portáteis, tais como: levantamentos de dados cadastrais a partir de fotografias aéreas; mapas comparativos e interativos; monitoramento de praças e vias em tempo real; passeios virtuais, etc. (KWIATEK, 2013). Uma parte considerável deste novo instrumental é baseada na utilização de fotografias interativas e de panoramas digitais, vi- sando justamente o potencial de experiência. Estes Elementos têm como principal finalidade codificar a experiência do observador no espaço concreto através de sua percepção visual, háptica e sonora no meio digital (LEITÃO, 2014). É um novo momento para os panoramas digitais.

Desde a grande popularização de smartphones e tablets, inúmeros aplicativos foram desenvolvidos para criar panoramas digitais: Dmd Panorama, Photosynth, YouSpin 360, Pano, 360 Panorama, do sistema iOS; Photaf Panorama, Panorama Camera, Panorama HD, Wondershare Panorama, Turn-me Panorama, do sistema Android, dentre muitos outros gratuitos ou de baixíssimo custo.

No entanto, todos estes aplicativos tem como foco a realizaçáo da fotografia de $360^{\circ}$, da "costura" do panorama através de fotos parciais e/ou sequencias, ou de uma varredura com a câmera do aparelho. Sua utilização se limita a capturar a fotografia no formato em $360^{\circ}$, e não o que se pode fazer a partir de sua realização. Os usos poderiam ir além: análises de espaços urbanos e suas correlaçôes; estudos sobre histórias alternativas das cidades; concepçóes digitais de um projeto arquitetônico ou urbano e sua imediata experimentaçáo na escala do observador; etc.

O presente artigo procurará enfatizar outro método de utilização dos aplicativos que apresentam panoramas: a história da cidade, em particular da área central da cidade do Rio de Janeiro. $\mathrm{O}$ artigo ira abordar e explorar a experiência imersiva no formato de $360^{\circ}$ não apenas através de panoramas, mas também por meio de vistas panorâmicas, desenhos e fotografias, realizados por notáveis pintores e fotógrafos que representaram a cidade do Rio de Janeiro no século 
XIX e início do século XX, confrontando este recorte histórico com imagens da cidade contemporânea. Para tanto, será apresentado o Panoramapp!, um aplicativo de nossa autoria, por meio do qual é possível interagir e pesquisar fotografias, pinturas e desenhos no formato de $360^{\circ}$ da área central da cidade do Rio de Janeiro.

\section{Objetivos: a experiência imersiva} através de panoramas digitais

É a partir da dualidade de momentos distintos, do início do século XIX e início do século XXI, que o tema da cidade enquanto experiência imersiva visual, háptica e sonora volta a aparecer. A outrora experiência espacial e sensorial, das rotundas dos Panoramas, pôde ser codificada, traduzida, reinterpretada, passando também a existir atualmente nas mídias digitais. Hoje, esta "outra” experiência imersiva apresenta características e potencialidades relacionadas ao seu momento e ao meio digital: a múltipla visão do todo; várias escalas de observação; a articulação entre diferentes tipos de representação digital como modelos 3D, vídeos, animaçóes; a livre programação de um hiperdocumento; dentre outras possibilidades. Se antes a experiência imersiva dos Panoramas era restrita apenas às suas rotundas, hoje, esta "outra" experiência pode ser contemplada tanto em interfaces planares de computadores, smartphones ou tablets, como também, em instalações panorâmicas com formatos circundantes.

A cidade do Rio de Janeiro representou e ainda representa um importante papel nestes dois momentos. Se por um lado, a urbe carioca sempre se mostrou curiosa e sedutora, por sua beleza cênica tropical e natureza exuberante para os viajantes do século XIX, tema de quatro Panoramas realizados a partir dos Morros do Castelo de Taunay e Burchell, Santo Antônio de Meirelles e Langerock, Santa Tereza de Dumoulin, por outro, o desejo crescente de conhecer a modificação dos principais espaços da cidade atual se comparados à sua história, as significativas e consequentes mudanças de sua área central, a possibilidade de um melhor controle e planejamento, revela-se desafiadora e interessante para arquitetos e urbanistas.

É neste sentido que o presente artigo se propóe a percorrer. Tem como principal objetivo explorar uma experiência imersiva no formato de $360^{\circ}$ através de panoramas, vistas panorâmicas, desenhos e fotografias, realizados por notáveis pintores e fotógrafos que representaram justamente a cidade do Rio de Janeiro no século XIX e início do século XX, confrontando com imagens da cidade contemporânea.

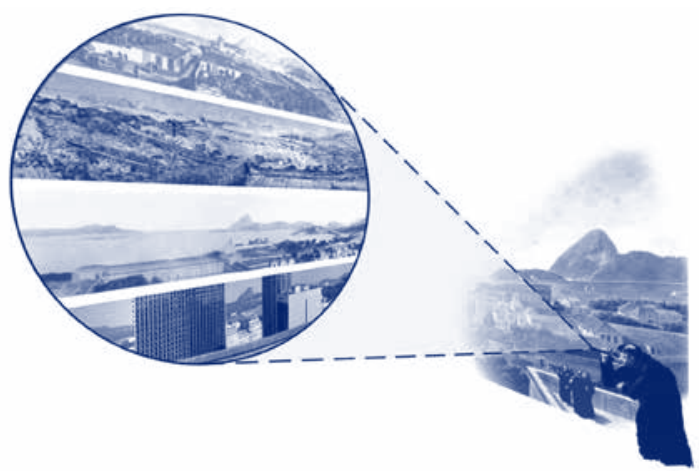

Figura l: A ideia original do Panoramapp: ver e interagir com a cidade ao longo do tempo através de seus panoramas.

\section{Método: o desenvolvimento e organização do aplicativo Panoramapp!}

Para a realização do Panoramapp!, foram estabelecidos três pontos principais na cidade do Rio de Janeiro: os morros do Castelo, Santo Antônio, e Santa Tereza, locais originais de onde foram realizados quatro dos seis panoramas de $360^{\circ}$. A partir do morro do Castelo foram coletados: o Panorama do viajante francês Félix-Émile Taunay de 1824 e o Panorama do naturalista inglês John William Burchell de 1825; para o morro de Santo Antônio: o Panorama de Victor Meirelles e Henri Langerock de 1888; e por fim, para o Morro de Santa Tereza: o Panorama de Dumoulin de 1910 (LEITÁO, 2009).

Estes quatro Panoramas estabelecem os principais locais de onde a cidade foi representada no formato de $360^{\circ}$ ao longo de sua história. E é a partir desta premissa que o Panoramapp foi organizado, definindo os momentos-chave e as camadas temporais durante o século XIX e início do século XX. Todas as demais informaçóes, tais como outros panoramas de $360^{\circ}$, vistas panorâmicas, desenhos, pinturas e fotografias, serão associadas por aproximação temporal e localizadas sobre estes panoramas. Além destes quatro panoramas históricos, serão apresentados para as seguintes áreas: Castelo, o panorama de Thomas Ender de 1817 , o panorama de Robert Burford de 1828, e o panorama do fotógrafo Santos Moreira de 1885; para Santo Antônio, o panorama de Briggs 1837, e o panorama de A. Ribeiro de 1910; e para Santa Tereza, o panorama do fotógrafo Ferrez de 1890. E a fim de facilitar o confrontamento das principais mudanças ocorridas na área central da cidade, três panoramas contemporâneos foram gerados.

A interatividade da interface será desenvolvida através de áreas sensíveis, de mapas temporais específicos para cada panorama, e por hotspots, podendo estar visíveis ou não. $\mathrm{O}$ aplicativo foi desenvolvido somente para sistema Android, com uma futura previsão para OS. Assim, o Panoramapp!, com suas diferentes camadas históricas, poderá oferecer uma nova leitura da área central da cidade do Rio de Janeiro, através de uma experiência imersiva, revelando de maneira inovadora as principais transformaçóes no decorrer dos séculos XIX e XX.

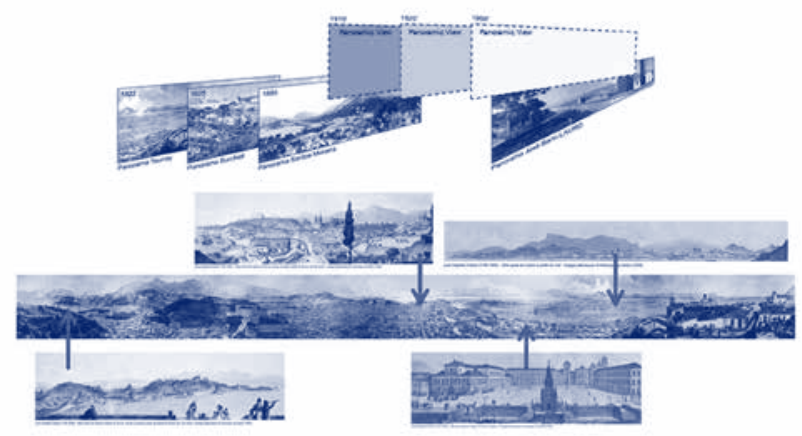

Figura 2: O método do Panoramapp: a organização dos panoramas históricos associados aos panoramas circulares de $360^{\circ}$ e a vistas panorâmicas da cidade. 


\section{Os resultados obtidos e perspectivas}

O principal resultado obtido foi o desenvolvimento do aplicativo em si. A partir de sua utilização foi possível contemplar, analisar e investigar as principais transformaçōes da cidade através de panoramas.

A expectativa inicial foi mantida. As reflexóes variam desde uma visão global, como também, a unidade, na escala do edifício, destacando as múltiplas leituras através dos panoramas. A simples constataçấo da sensível mudança da paisagem da cidade, com a diminuiçâo da presença da natureza dentro da própria área central, tão ricamente desenhada e explorada pelos primeiros panoramistas europeus; o crescente adensamento e desordenamento urbano, fortemente presentes já a partir do final do século XIX, e agravados por todo o século XX; a modificação das principais praças, ruas e avenidas.

Além da comparação entre o que foi representado nos panoramas, nas vistas panorâmicas, nos desenhos e nas fotografias de $360^{\circ}$, a utilizaçấo do Panoramapp! permitiu também comparar as diferentes técnicas de representaçấo gráfica utilizadas. Tal observaçáo náo se deve exclusivamente à existência de vários autores ao longo do tempo, mas também para qual objetivo os panoramas foram realizados: se meramente romântico e pictórico, com um desenho de cidade ideal; com precisão topográfica, com uma minuciosa descrição dos principais edifícios e marcos da paisagem; desenho da mesma paisagem romântica já modificada com anseios de progresso; desenho da cidade com intençôes de mapeamento/ cadastramento, etc.

Cabe ressaltar que o Panoramapp! acabou se transformando em um grande 'banco de imagens' da área central do Rio de Janeiro entre os séculos XIX e início do XX, o que náo havia sido vislumbrado anteriormente. A ideia inicial seria apenas relacionar os principais panoramas e confrontá-los: analisar as principais diferenças e investigar o que aparece em um panorama, mas náo em outro, e ainda, contemplar como um determinado elemento aparece representado por um pintor, e posteriormente por um fotógrafo; e etc.

No entanto, a possibilidade de associar aos panoramas a camadas temporais, e principalmente, poder ancorar outras informaçōes sobre a cidade - como vistas panorâmicas, desenhos, gravuras, mapas e fotografias - em sua ampla imagem circular de $360^{\circ}$, enriqueceu em muito a experiência oferecida pelo aplicativo. À medida que as bases das camadas temporais foram estabelecidas pelos panoramas, foi possível também determinar como seria o agrupamento das demais informaçóes afins, sempre aproximadamente no mesmo período em que foram realizados.

Outro resultado não vislumbrado ao longo do processo de elaboraçấ, mas que se consolidou com uma importante contribuiçấo, foi a possibilidade de utilizaçấo do Panoramapp! in loco, percorrendo justamente os fragmentos das camadas históricas da cidade. Poder subir em um alto edifício da área central da cidade, ou ainda, em um espaço remanescente representado em um dos antigos panoramas, podendo ver e comparar como era a cidade nos respectivos momentos e como hoje a mesma se encontra, enriqueceu muito a experiência do Panoramapp!

Figure : A Interface do Panoramapp! com o Panorama do Morro do Castelo de W. J. Burchell de 1828, com hotspots visíveis.

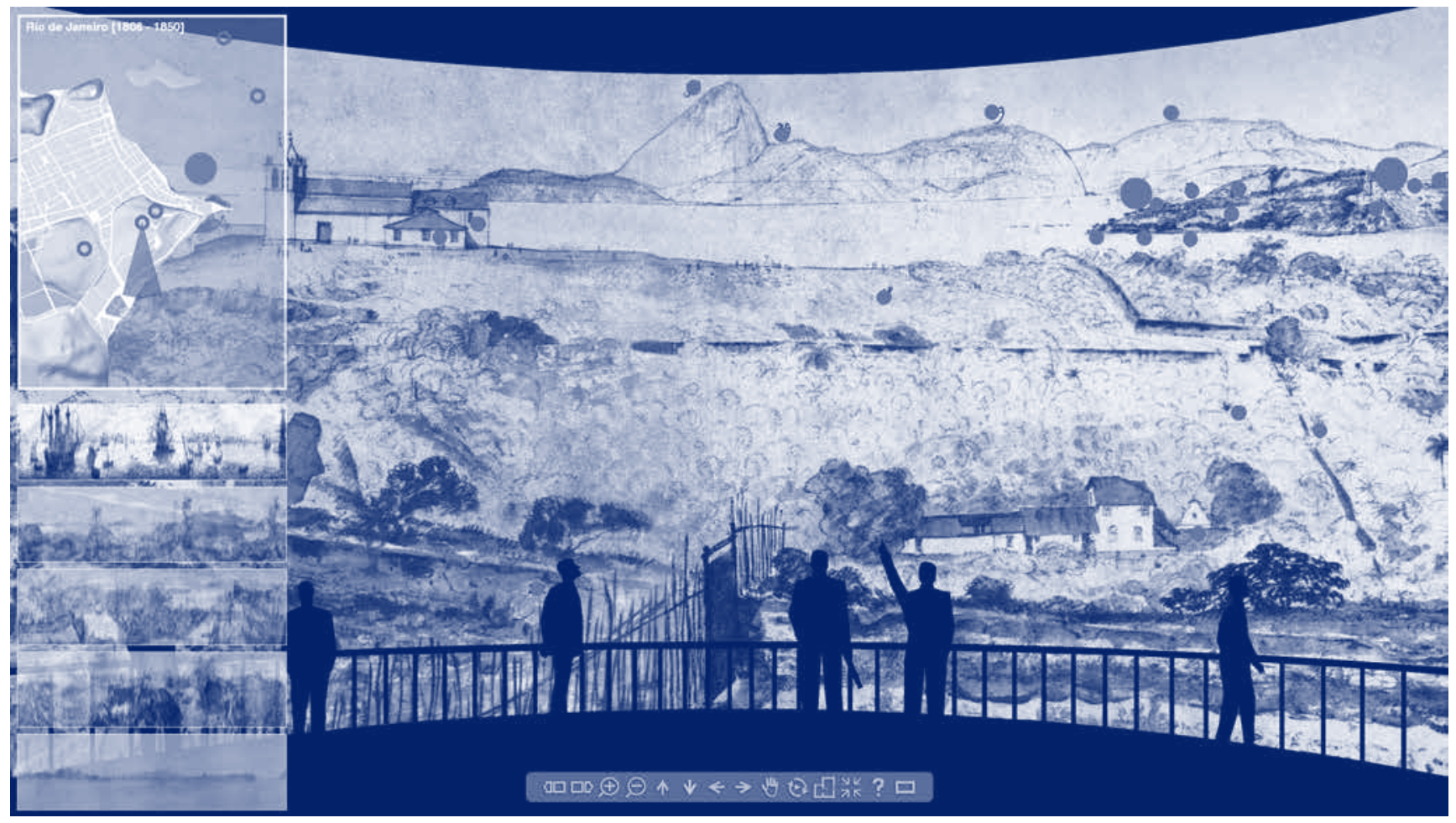




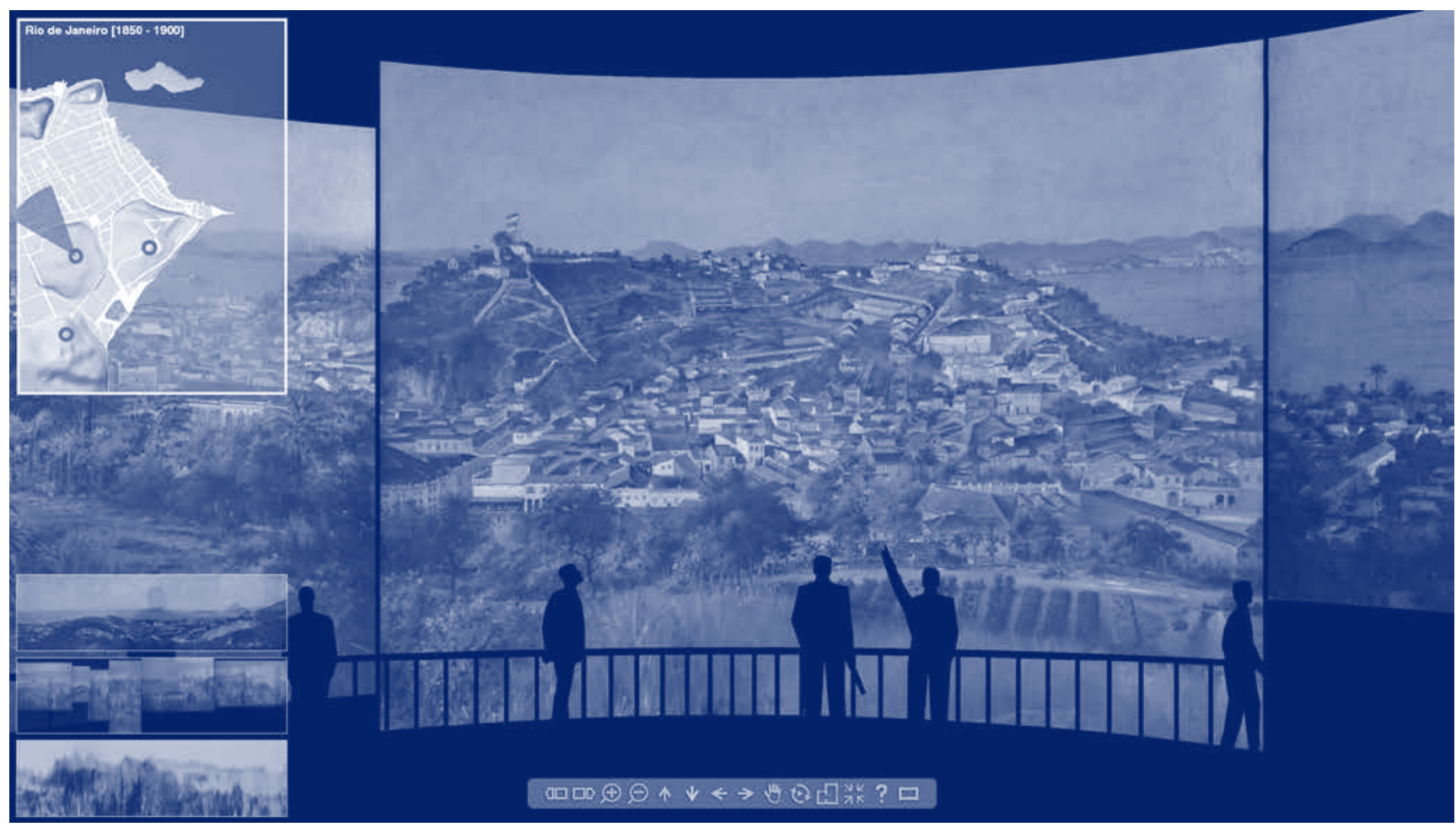

Figure 4: A Interface do Panoramapp! com o Panorama do Morro do Santo Antônio de V. Meirelles e H. Langerock de 1888.

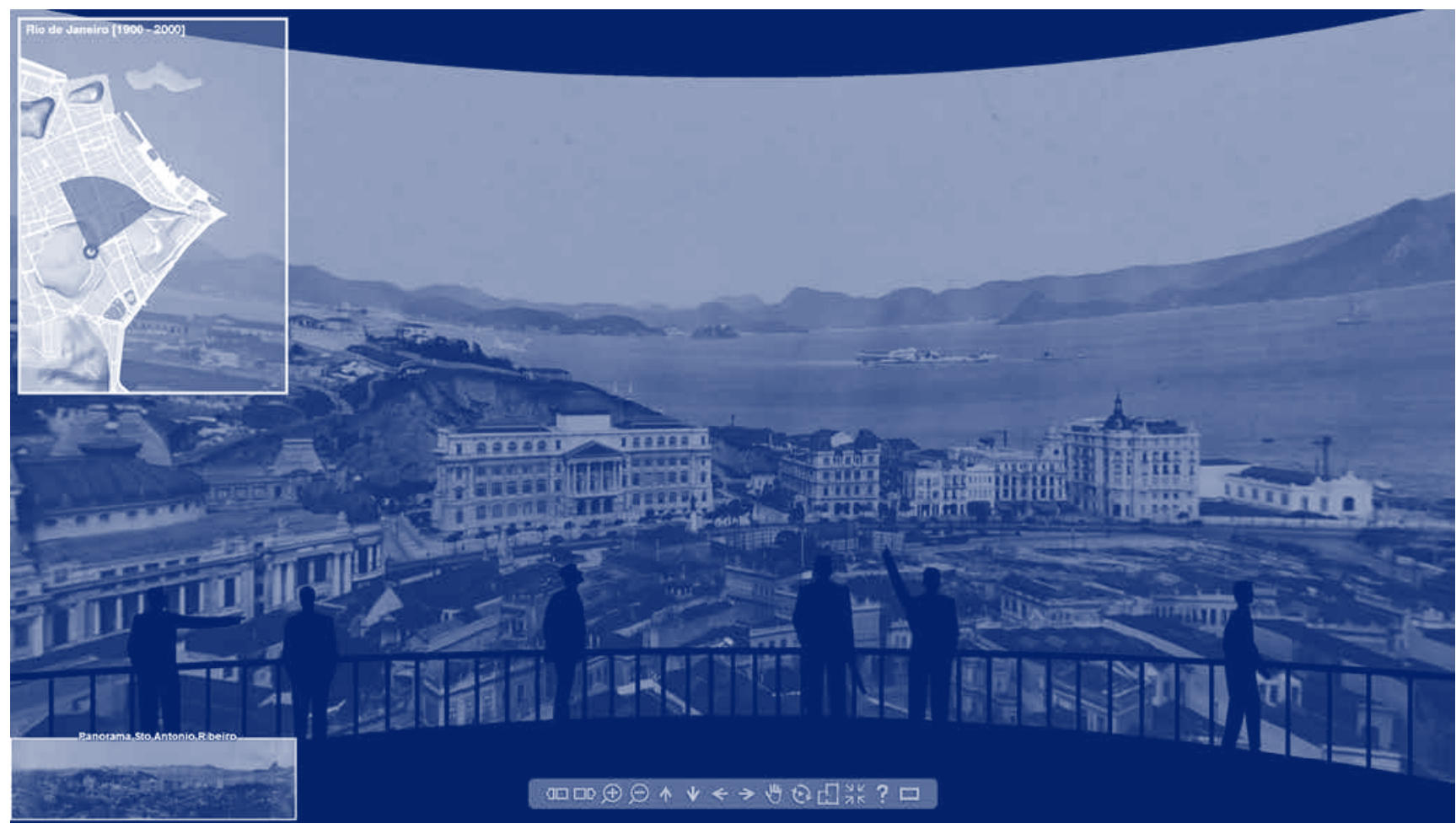

Figure 5: A Interface do Panoramapp! com o Panorama do Morro do Santo

Antônio de A. Ribeiro de 1910. 


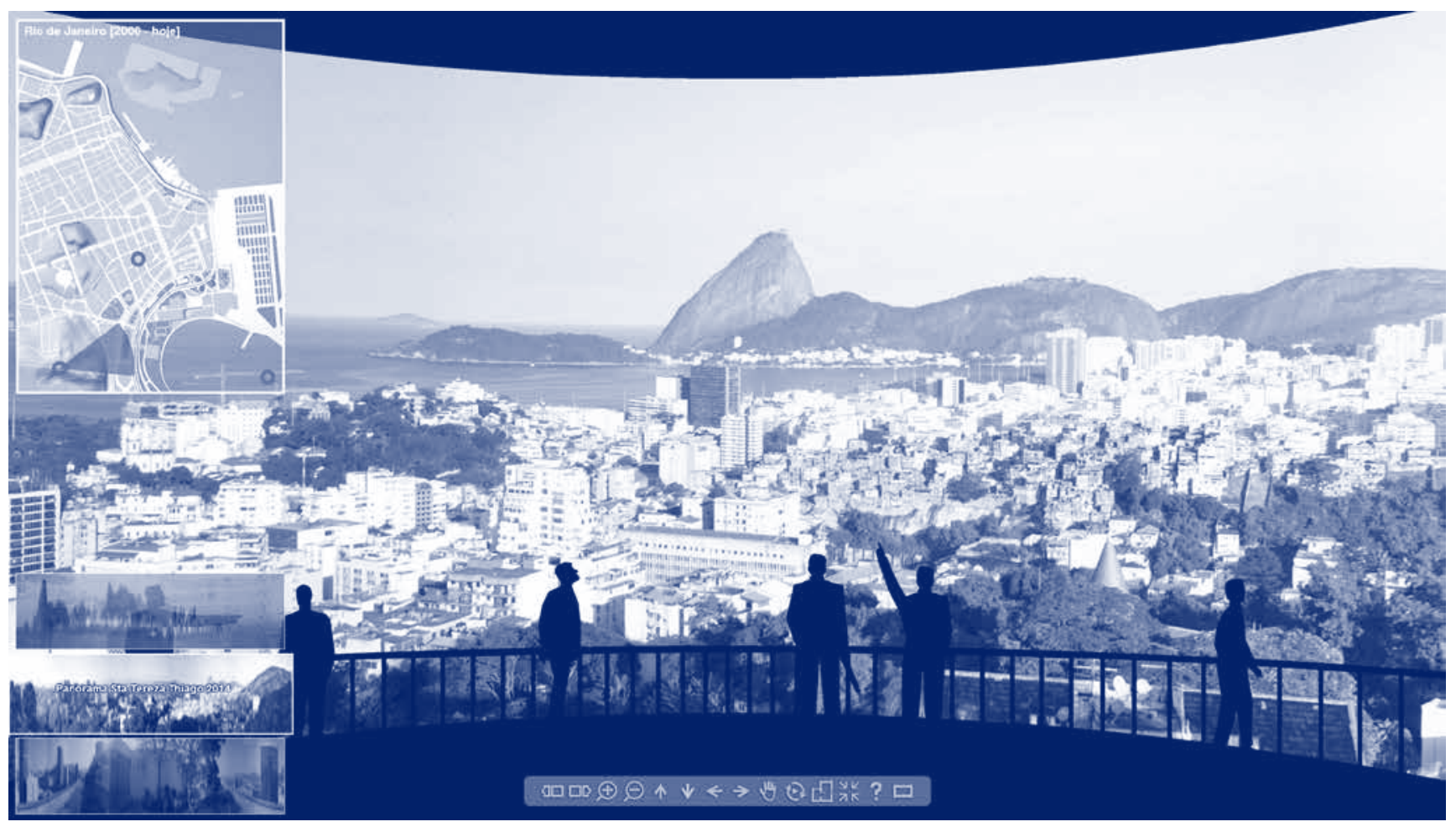

Figure 6: A Interface do Panoramapp! com o Panorama do Morro de Santa Tereza de Thiago Leitáo de 2013.

\section{Agradecimentos}

Este artigo está relacionado a tese "O Panorama e a experiência imersiva: do espetáculo de entretenimento aos meios digitais”, realizada no LAURD - Laboratório de Análise Urbana e Representaçâo Digital no Programa de Pós-Graduação em Urbanismo da FAU/ UFRJ. Agradecemos a Roberto Segre e José Barki, e aos demais professores, pesquisadores e alunos envolvidos pela participação e consideraçóes realizadas sobre este trabalho.

\section{Referências}

Calleja, G. In-Game: From Immersion to Incorporation. Cambridge, MA: MIT Press, 2011.
Grau, O. Arte Virtual: da ilusão à imersão. São Paulo: Editora UNESP; Editora SENAC São Paulo, 2007.

Kwiatek, K. A Critical Practice-based Exploration of Intectavice Panoramas' role in helping to preserve Cultural memory. Thesis (Phd in Philosophy) - University of Plymouth, 2013, 364f.

Leitão de Souza, T. O panorama: da representação-pictórico espacial às experiências digitais. Dissertação. (Mestrado em Urbanismo) - Universidade Federal do Rio de Janeiro, PROURB / FAU, 2009, 223f.

Leitáo de Souza, T. O panorama e a experiência imersiva: do espetáculo de entretenimento aos meios digitais. Tese (Doutorado em Urbanismo) - Universidade Federal do Rio de Janeiro, PROURB / FAU, 2014, 241f 